\title{
NOTE ON A THEOREM OF PH. GILBERT'S REGARDING THE DIFFERENTIATION OF A SPECIAL JACOBIAN.
}

\section{By Thomas Muir, LL.D.}

(Received November 5, 1913.)

1. The theorem in question is the subject of a memoir presented to the Belgian Academy in 1869.* As stated by its author, it may be formulated as follows: If $\mathrm{f}_{\mathrm{s}}, \mathrm{f}_{2}, \ldots, \mathrm{f}_{n}$ be functions of $\mathrm{u}_{\mathrm{r}}, \mathrm{u}_{2}, \ldots, \mathrm{u}_{n}$, and if the latter be implicit functions of two sets of independent variables

and be such that

$$
\begin{aligned}
& x_{1}, x_{2}, \ldots, x_{n} \\
& \boldsymbol{a}_{1}, \boldsymbol{a}_{2}, \ldots, \boldsymbol{a}_{n}
\end{aligned}
$$

$$
\frac{\partial u_{\mu}}{\partial x_{i}}=\phi_{i} \frac{\partial u_{\mu}}{\partial a_{i}}
$$

where each $\phi$ is an explicit function of the u's, then

$$
\frac{\partial}{\partial x_{i}}\left\{\frac{\partial\left(f_{\mathrm{I}}, f_{2}, \ldots, f_{\mu}\right)}{\partial\left(\boldsymbol{a}_{\mathrm{I}}, \boldsymbol{a}_{2}, \ldots, \boldsymbol{a}_{\mu}\right)}\right\}=\frac{\partial}{\partial \boldsymbol{a}_{i}}\left\{\phi_{i} \frac{\partial\left(f_{\mathrm{I}}, f_{2}, \ldots, f_{\mu}\right)}{\partial\left(\boldsymbol{a}_{\mathrm{I}}, \boldsymbol{a}_{2}, \ldots, \boldsymbol{a}_{\mu}\right)}\right\}-\frac{\partial\left(f_{\mathrm{I}}, f_{2}, \ldots, f_{\mu}, \phi_{i}\right)}{\partial\left(\boldsymbol{a}_{\mathrm{I}}, \boldsymbol{a}_{2}, \ldots, \boldsymbol{a}_{\mu}, \boldsymbol{a}_{i}\right)}
$$

2. For the sake of clearness, and, indeed, of accuracy, it would have been better not to have used in the concluding equation the same subscripts $\mu$ and $i$ as are used in the hypothetical equation, unless an indication were given on both occasions as to the range which each of them was understood to cover. Doubtless what Gilbert had in his mind could have been expressed by annexing to the hypothetical equation the explanation

$$
\left.\begin{array}{l}
\mu=1,2, \ldots, n \\
i=1,2, \ldots, n
\end{array}\right\}
$$

* Sur une propriété des déterminants fonctionnels, et son application au développement des fonctions implicites. Nouv. Mém. de l'Acad. roy. de Belgique, xxxviii, pp. 1-12. 
and by using in the concluding equation $\nu, j$ in place of $\mu, i$ with the explanation

$$
\left.\begin{array}{l}
\nu=1,2, \ldots, n \\
j=1,2, \ldots, n
\end{array}\right\}
$$

The theorem would then have been satisfactory on the score of accuracy, the $n^{2}$ given equations being sufficient to ensure the validity of the $n^{2}$ resulting equations. It would still, however, have been lacking on the score of definiteness, because of the failure to indicate how many of the given equations were necessary for the validity of any particular one of the resulting equations.

3. Very probably this neglect arose from the fact that the author was concerned with a particular application of his theorem, namely, towards the generalization of Lagrange's expansion of $\mathrm{F}(u)$ in a series of ascending powers of $x$ when

$$
u=a+x f(u),
$$

and that the enunciation in question sufficed for the purpose he had in view. Probably also this accounts for the care taken to specify in the enunciation certain functions as being explicit and certain others implicit.

4. Gilbert's memoir, however, calls for attention altogether apart from these considerations, the proof which he adduces in support of his theorem being far from satisfying. What he gives is merely a verification of the three simplest cases, with the second case resting on the first, and the third on the first and second. In many instances this might be quite convincing as forming the basis of a proof by the method of so-called 'mathematical induction' : but here it is not so.

The purpose of the present note is to effect an improvement under both the heads mentioned.

5. When divested of all superfluities the theorem is: If the differential coefficients of $\mathrm{y}_{\mathrm{I}}, \mathrm{y}_{2}, \ldots, \mathrm{y}_{n}$ with respect to $\mathrm{x}$ be proportional to the differential coefficients with respect to $\xi$, the common ratio being $\mathrm{R}$, and if the $\mathrm{y}$ 's be also functions of $\mathrm{w}_{\mathrm{I}}, \mathrm{w}_{2}, \ldots \mathrm{w}_{n}$, then

$$
\partial\left\{\frac{\partial\left(y_{1}, y_{2}, \ldots, y_{n}\right)}{\partial\left(w_{1}, w_{2}, \ldots, w_{n}\right)}\right\}=\frac{\partial}{\partial \xi}\left\{\mathrm{R} \frac{\partial\left(y_{1}, y_{2}, \ldots, y_{n}\right)}{\partial\left(w_{1}, w_{2}, \ldots, w_{n}\right)}\right\}-\frac{\partial\left(y_{1}, \ldots, y_{n}, \mathrm{R}\right)}{\partial\left(w_{1}, \ldots, w_{n}, \xi\right)} .
$$

In the proof of it we shall take $n=3$, not, as will be seen, because the method is lacking in generality, but merely in order to save space in writing. 
Looking first to the right-hand member, we see that the differentiation there indicated with respect to $\xi$ gives

$$
\frac{\partial R}{\partial \xi} \cdot \frac{\partial\left(y_{1}, y_{2}, y_{3}\right)}{\partial\left(w_{1}, w_{2}, w_{3}\right)}+\mathrm{R} \frac{\partial}{\partial \xi}\left\{\frac{\partial\left(y_{1}, y_{2}, y_{3}\right)}{\partial\left(w_{1}, w_{2}, w_{3}\right)}\right\},
$$

and that the Jacobian following this having $\partial \mathrm{R} / \partial \xi$ for the element in the place 4,4 may be partitioned into two parts, one consisting of those terms of the Jacobian which involve the element $\partial \mathrm{R} / \partial \xi$, and the other being the aggregate of the terms which are independent of $\partial R / \partial \xi$. The former, however, is equal to

$$
-\frac{\partial\left(y_{1}, y_{2}, y_{3}\right)}{\partial\left(w_{1}, w_{2}, w_{3}\right)} \cdot \frac{\partial \mathrm{R}}{\partial \xi}:
$$

and so of the four expressions thus obtained, the first and third cancel each other, leaving the right-hand member transformed into

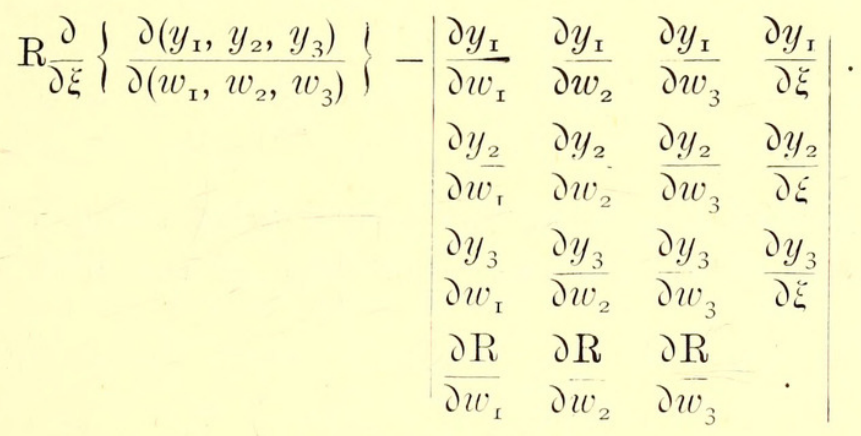

Turning next to the left-hand member, and using Jacobi's theorem regarding the differentiation of a determinant, we can express it as the sum of three determinants, the first differing from $\partial\left(y_{1}, y_{2}, y_{3}\right) \partial /\left(w_{1}, w_{2}, w_{3}\right)$ in having the operational symbol $\partial / \partial x$ prefacing every element of the first column, and the second and third having the same change made on the second and third columns respectively. This sum we may indicate by

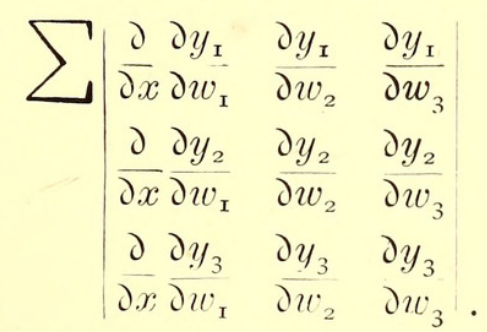

But now every one of the elements here which involve differentiation with respect to $x$ is transformable as follows :-

$$
\begin{aligned}
\frac{\partial \partial y_{r}}{\partial x \partial w_{*}} & =\frac{\partial}{\partial w_{s}} \partial y_{r} \\
& =\frac{\partial}{\partial w_{1}}\left\{\mathrm{R} \frac{\partial y_{r}}{\partial \xi}\right\} \\
& =\mathrm{R} \frac{\partial^{2} y_{r}}{\partial w_{s} \partial \xi}+\frac{\partial \mathrm{R}}{\partial w_{s}} \frac{\partial y_{r}}{\partial \xi} ;
\end{aligned}
$$


and consequently each of the three determinants is partitionable into two determinants. These six, however, may be combined into two triads, one being representable by

$$
\sum \begin{array}{lll}
\mathrm{R} \frac{\partial y_{1}}{\partial \xi \partial w_{1}} & \frac{\partial y_{1}}{\partial w_{2}} & \frac{\partial y_{1}}{\partial w_{3}} \\
\mathrm{R} \frac{\partial \partial y_{2}}{\partial \xi \partial w_{1}} & \frac{\partial y_{2}}{\partial w_{2}} & \frac{\partial y_{2}}{\partial w_{3}} \\
\mathrm{R}_{\partial \xi}^{\partial} \frac{\partial y_{3}}{\partial w_{1}} & \frac{\partial y_{3}}{\partial w_{2}} & \partial y_{3} \\
\partial w_{3}
\end{array},
$$

and the other by

$$
\sum \begin{array}{lll}
\frac{\partial R}{\partial w_{1}} \frac{\partial y_{1}}{\partial \xi} & \frac{\partial y_{1}}{\partial w_{2}} & \frac{\partial y_{1}}{\partial w_{3}} \\
\frac{\partial R}{\partial} \frac{\partial y_{2}}{\partial w_{1}} & \frac{\partial y_{2}}{\partial \xi} & \frac{\partial y_{2}}{\partial w_{2}} \\
\frac{\partial R}{\partial w_{1}} \frac{\partial y_{3}}{\partial \xi} & \frac{\partial y_{3}}{\partial w_{2}} & \frac{\partial y_{3}}{\partial w_{3}}
\end{array} .
$$

A further step is then suggested, the former triad being, by the abovementioned theorem of Jacobi, the equivalent of the first part of $(\boldsymbol{a})$, namely,

$$
\mathrm{R}_{\partial \xi}^{\partial} \frac{\partial\left(y_{1}, y_{2}, y_{3}\right)}{\partial\left(w_{1}, w_{2}, w_{3}\right)}
$$

and the latter triad being condensable into the four-line determinant which is the second part.

The theorem is thus established. 


\section{$2 \mathrm{BHL}$ Biodiversity Heritage Library}

Muir, Thomas. 1914. "NOTE ON A THEOREM OF PH. GILBERTS REGARDING THE DIFFERENTIATION OF A SPECIAL JACOBIAN." Transactions of the Royal Society of South Africa 4, 139-142. https://doi.org/10.1080/00359191409519522.

View This Item Online: https://www.biodiversitylibrary.org/item/181590

DOI: https://doi.org/10.1080/00359191409519522

Permalink: https://www.biodiversitylibrary.org/partpdf/175532

\section{Holding Institution}

Smithsonian Libraries

\section{Sponsored by}

Biodiversity Heritage Library

\section{Copyright \& Reuse}

Copyright Status: Not in copyright. The BHL knows of no copyright restrictions on this item.

This document was created from content at the Biodiversity Heritage Library, the world's largest open access digital library for biodiversity literature and archives. Visit BHL at https://www.biodiversitylibrary.org. 